\title{
SERUM SOLUBLE ADHESION MOLECULES (SICAM-1, sVCAM-1 AND SE-SELECTIN) IN HEALTHY SCHOOL AGED CHILDREN AND ADULTS
}

\author{
Ctirad Andrýs ${ }^{1}$, Oldř̈ich Pozler ${ }^{2}$, Jan Krejsek ${ }^{1}$, Václav Derner ${ }^{1}$, Marcela Drahošová ${ }^{1}$, Otakar Kopecký ${ }^{1}$ \\ University Teaching Hospital in Hradec Králové: Department of Clinical Immunology and Allergology ${ }^{1}$, Department of \\ Pediatrics $^{2}$
}

\begin{abstract}
Summary: The aim of this study was to map normal levels of serum soluble isoforms of adhesion molecules in relation to age and sex in the group of school-aged children. sICAM-1, sVCAM-1 and sE-selectin were determined in the group of 158 normal children subdivided into two subgroups; 6-10 years (68 children, median age 8 years) and 11-15 years ( 90 children, median age 12 years) and in 70 normal adult blood donors ( 25 females and 45 males, median age 46 years). The levels of sICAM-1 and sE-selectin fell down significantly over the age range 6-15 years, while the level of sVCAM-1 was remained. Age-related normal ranges were established using correlation analysis and were expressed as the $5 \%-95 \%$ percentiles intervals: sICAM-1 $206.8-486.8 \mathrm{ng} / \mathrm{ml}$, sE-selectin $36.7-153.2 \mathrm{ng} / \mathrm{ml}$ in the group of 6-10 years old children, sICAM-1 184.1 - $354.0 \mathrm{ng} / \mathrm{ml}$, sE-selectin $29.9-114.1 \mathrm{ng} / \mathrm{ml}$ in group of 11-15 years old children. The levels of sVCAM-1 were 359.6 - 822.0 $\mathrm{ng} / \mathrm{ml}$ and were constant within the examined age interval from 6 to 15 years. The influence of sex was also assayed and it was not statistically significant in any age category tested. Normal ranges of sICAM-1 $(60.2-218.4 \mathrm{ng} / \mathrm{ml})$, sE-selectin $(8.3-116.9 \mathrm{ng} / \mathrm{ml})$ and sVCAM-1 $(338.0-1148.0 \mathrm{ng} / \mathrm{ml})$ were established for adult population of healthy blood donors using the same methods.
\end{abstract}

Key words: Children; Normal levels; sE-selectin; sICAM-1; sVCAM-1

\section{Introduction}

Leukocyte adhesion is a crucial step in the development of both normal immune response and inflammation $(4,9)$. Adhesion of leukocytes is mediated through the multiple interactions between adhesion molecules and their ligands. Recently we have learned that soluble isoforms of these adhesion structures can be found in the circulation and their levels can serve as markers of disease activity $(7,21)$. The information obtained from the measurement of soluble adhesion molecules can be interpreted in several different ways. The expression and subsequent release of soluble cellular adhesion molecules is mediated by proinflammatory stimuli both exogenous and endogenous origins such as endotoxin, histamin, thrombin, and various cytokines. Soluble cellular adhesion molecules may be regarded simply as the markers of the presence and intensity of inflammation. The clinical utility of monitoring levels of soluble adhesion molecules is not yet established, but it is suggested that the availability of commercial assay kits should allow their evaluation in many clinical settings (8). There is a demand for studies that would delineate the parameters of the immune system in healthy population and establish their normal ranges for clinical use. Particularly interesting is the situation in children's population where age trends may be expected and blood samples are not readily available. The aim of this study is to establish normal ranges for serum levels of sICAM-1, sE-selectin and sVCAM-1 and their age related changes in healthy children's population from 6 to 15 years of age.

\section{Materials and Methods}

\section{Subjects}

The serum samples were obtained from 158 healthy children ( 81 females, 77 males) aged from 6 to 15 years. The median age was 10 years. There were at least ten children in any one-year interval examined. Serum samples were drawn for the purpose of the vaccination surveillance study organized by Military Medical Academy in Hradec Kralove, Czech Republic. Neither additional venipuncture nor larger volume of blood was required. The adult group consisted of 70 healthy blood donors ( $25 \mathrm{fe}$ males and 45 males, median age 46 years, range $22-65$ years). All subjects were interviewed and examined by the physician before blood sampling. This study was approved by the institutional ethical committee and informed consent was obtained from parents of all participants in this study. 


\section{Blood sampling}

Peripheral blood samples were collected by the venipuncture into sterile tube (Sarstedt, Germany). Blood samples were collected between 8 and 9 hours a.m. after 10 hours of fasting and after $15 \mathrm{~min}$ of rest. All participants were asked in advance to avoid unusual physical load for 12 hours before blood drawing. Blood was left at room temperature for 1.5 hours. Serum samples were collected after centrifugation and were stored frozen at $-40{ }^{\circ} \mathrm{C}$ up to 3 months and thawed only once immediately before processing.

\section{Measurement of soluble forms of adhesion molecules}

Serum concentrations of sICAM-1, sVCAM-1 and sEselectin were obtained by use commercial ELISA kits Parameter Human Soluble ICAM-1, Parameter Human Soluble VCAM-1 and Parameter Human Soluble E-Selectin manufactured by RD Systems (Minneapolis, MN, USA). ELISA technique was performed according to the manufacturers' instructions. Briefly, diluted samples, standards and controls were incubated in microtiter wells coated with monoclonal antibodies anti-human sE-selectin, sICAM-1 or sVCAM-1. Coupled human sICAM-1, sE-selectin and sVCAM-1 were then detected by secondary antibody conjugated to horseradish peroxidase. Final color reactions were measured by Multiscan MCC 340 reader (Flow Lab, UK) and data were processed automatically. All measurement were done with the same batch and in a duplicate.

\section{Statistical analysis}

The analysis was done using SigmaStat 2.0 statistical software (Jandel Corporation, USA). The normal distribution of data was proved. The differences between groups were calculated by t-test or Mann-Whitney Rank Sum test and correlation analysis was performed according to Pearson or Spearman tests.

\section{Results}

The statistical differences between genders in the whole group were tested by the nonparametric Mann-Whitney Rank Sum Test. No statistical differences in any parameter tested (sICAM-1, sVCAM-1 and sE-selectin) were found. The possibility that these parameters are age-related was evaluated. The statistically significant decline in the level of sICAM-1 (coefficient of correlation $r=-0.326, p<0.001$ ) and E-selectin (coefficient of correlation $r=-0.283$, $p<$ 0.001 ) was found in contrast to the level of sVCAM-1 which remained unchanged $(r=-0.056, p<0.05)$. Similar statistically significant age-related correlations for both sICAM-1 (males $r=-0.341, p=0.002$, females $r=-0.296, p=0.007$ ) and sE-selectin (males $\mathrm{r}=-0,241, \mathrm{p}=0,035$, females $\mathrm{r}=-0,331$, $\mathrm{p}=0,003$ ) were reached when the group was subdivided according to the gender. No such correlation was found for sVCAM-1. Age-related trends in the levels of soluble adhesion molecules are shown in Fig. 1-3.

The optimal subdivision of the whole examined group to the intervals of age according to the trends in the levels of soluble adhesion molecules sICAM-1 and sE-selectin was calculated. The testing was started at the age of six years and was increased gradually within the interval of one year. The correlation with age was always calculated. No statistical correlation of age and the levels neither sICAM1 nor sE-selectin was found for the 6 - 10 years old children. This fact was the reason to establish the first reference group. The second group was delineated by the same approach for children 11 - 15 years old. The calculated relations were confirmed by additional statistical tests. Statistically significant differences in the serum level of both sICAM-1 $(p<0.001)$, and sE-selectin $(p=0.005)$ but not for the level of sVCAM-1 $(p=0.320)$ were calculated.

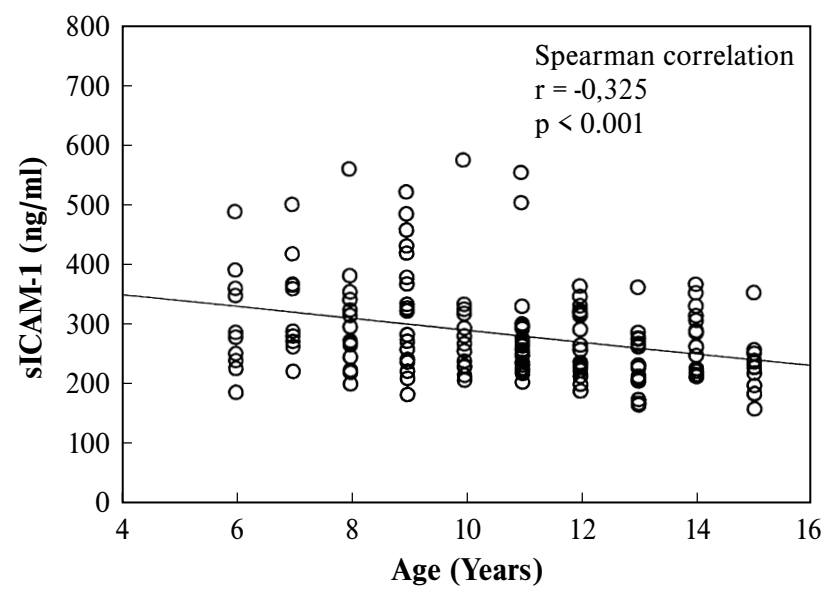

Fig. 1: Relationship between serum levels of sICAM-1 and age in the whole group of children (6-15 years old). The solid line represent regression curve.

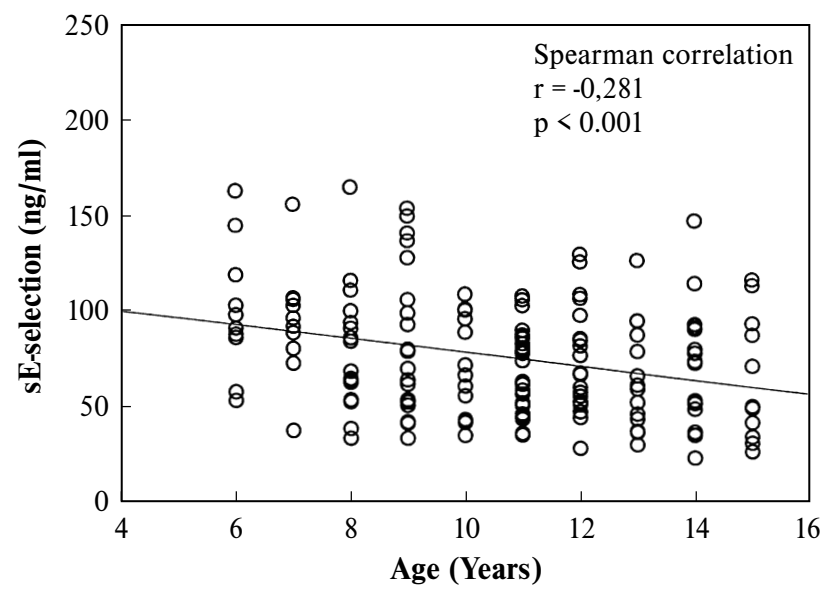

Fig. 2: Relationship between serum levels of sE-selectin and age in the whole group of children (6-15 years old). The solid line represent regression curve. 


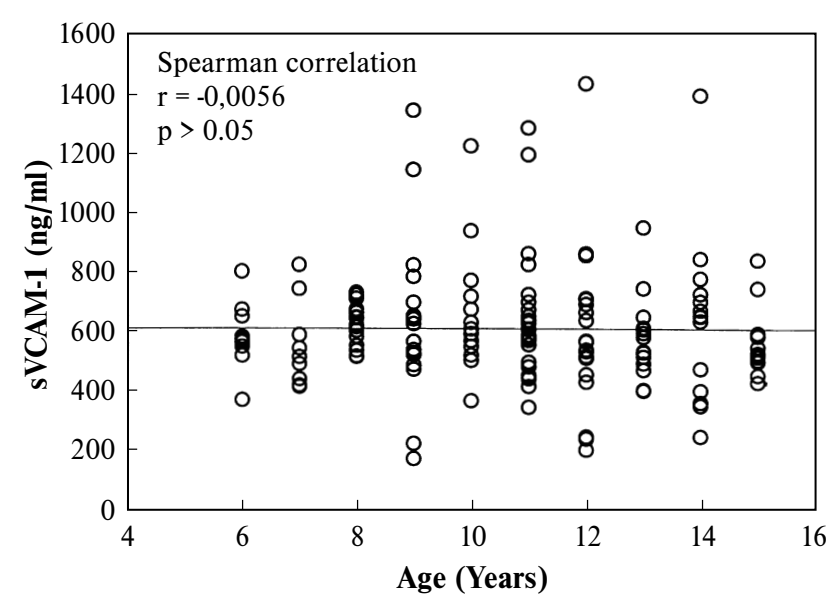

Fig. 3: Relationship between serum levels of sVCAM-1 and age in the whole group of children (6-15 years old). The solid line represent regression curve.

The serum values of sICAM- 1 which fall into the interval $5 \%$ - 95\% percentiles were from 206.8 to $486.8 \mathrm{ng} / \mathrm{ml}$ for 6 - 10 years old children and from 184.1 to $354.0 \mathrm{ng} / \mathrm{ml}$ for 11 - 15 years old children. The serum values of sE-selectin which fall into the interval $5 \%-95 \%$ percentiles were from 36.7 to $153.2 \mathrm{ng} / \mathrm{ml}$ for 6 - 10 years old children and from 29.9 to $114.1 \mathrm{ng} / \mathrm{ml}$ for 11 - 15 years old children. The serum values of sVCAM-1 which fall into the interval 5\% $95 \%$ percentiles were from 359.6 to $822.0 \mathrm{ng} / \mathrm{ml}$ for $6-15$ years old children. These intervals are suggested as reference in our laboratory.

Statistically significant increase in both sICAM-1 ( $p<$ 0.001 ), and sE-selectin ( $p<0.001$ ) but not in sVCAM-1 was observed comparing group of children $11-15$ years old to adults.

The same approach was used for the calculation of reference values of sICAM-1 (160.2 - $218.4 \mathrm{ng} / \mathrm{ml})$, sE-selectin $(8.3-116.9)$ and sVCAM-1 $(338.0-1148.0 \mathrm{ng} / \mathrm{ml})$ for adults. This group was not subdivided into males and females because there were no statistically significant differences in any parameter tested according to the gender.

\section{Discussion}

The trapping of leukocytes from the blood stream and their subsequent rolling along the activated endothelial cell lining of postcapilary venules are the earliest signs of inflammation. Rolling is an essential element of the multistep cascade leading to the leukocyte recruitment into sites of inflammation. It is mediated by the interactions between E-selectins on the surface of activated endothelial cells and their ligands, which are heavily glycosylated surface molecules of leukocytes e.g. CD15 molecule of granulocytes. Granulocytes, monocytes and a subset of memory $\mathrm{T}$ cells could be bound through this interaction. Next step is mediated through the interaction between adhesion molecules belonging into the families of immunoglobulins and integ- rins. ICAM-1 will bind cells expressing the beta ${ }_{2}$ integrins including lymphocytes, granulocytes, and monocytes. VCAM-1 will bind only cells expressing the beta integrin VLA-4 including lymphocytes, eosinophils, basophils and monocytes $(9,14)$.

Membrane adhesion molecules are shed into the body fluids by the proteolytic cleavage or by alternative splicing on the level of mRNA (8). The elevated levels of soluble adhesion molecules are found in the serum of patients with various inflammatory diseases and may provide some useful diagnostic or prognostic information (7). The serum or plasma levels of soluble forms of adhesion molecules are reported to be elevated in patients with various immunopathological diseases such as atopic dermatitis and psoriasis (6), vasculitis and scleroderma (5), $\mathrm{Sj}$ (gren syndrome $(11,12)$, atherosclerosis $(2,3)$, systemic lupus erythematosus $(22)$ as well as in malignancies $(1,23)$ and in infectious disorders such as septic shock (18).

It is well known that macromolecules such as cytokines or soluble adhesion molecules which are presented in minute amounts in serum or plasma are prone to be degraded by the action of proteolytic enzymes or self destruction. Blood samples have to be processed in standardized way and serum samples have to be frozen immediately. Blockage of proteolytic enzymes by inhibitors is recommended. It is necessary to avoid repeated thawing-freezing procedures.

Blood samples were stored at $-40{ }^{\circ} \mathrm{C}$ within 3 months and were thawed only once. Nash and co-workers tested the influence of number of freeze-thaw cycles and prolonged storage on values of soluble adhesion molecules and found no significant changes after multiple freeze-thaw cycles and a few years of storage at -70 (C. Differences were less significant than the variability during measurement (17).

Blood samples were drawn in the narrow period between 8 and 9 hours in the morning to eliminate the influence of circadian rythm (15). All participants were asked to obstain from unusual physical load for 12 hours before the venipuncture because it is reported that physical activities can affect the results of such study (10).

Studies in adults suggest that levels of sE-selectin, sICAM-1 and sVCAM-1 are constant from 18 to 65 years $(8,18,19)$. These findings we confirmed in our study where we found no statistically significant correlation of levels of sE-selectin, sICAM-1 and sVCAM-1 with age in healthy persons aged from 22 to 65 years.

The situation during childhood is rather different. It could be expected that there are changes in serum levels of soluble adhesion molecules during the normal development. These changes could be so important that it is not recommended to use normal adulthood ranges for evaluation of children's population. It is well known from the estimation of other parameters of the immune system i.e. immunoglobulins that it is useful to stratify children's population into several age groups.

Kurukawa and co-workers reported higher levels of sICAM-1 in 10 normal pre-school children compared to 10 
school age children (13). In another study, values of these three soluble cell adhesion molecules in 48 healthy children (median age 5 years) were found to be approximately double of those seen in adults (16). Similar results were obtained in study of Sack and co-workers (20). Nash and co-workers in a large study observed significant correlation of levels of sE-selectin, sICAM-1 and sVCAM-1 with age between 9 and 16 years at regular 2-year intervals (17). These results are very similar to our own findings concerning sICAM-1 and sE-selectin. In case of sVCAM-1 our result are not consistent with this study. There was no significant correlation of sVCAM-1 and age in children from 6 to 15 years, despite the fact that the levels of sVCAM-1 were significantly higher in 10 - 15 years old children compared to adults $(\mathrm{p}<0.001)$.

The physiological role of changes in the levels of soluble adhesion molecules during maturation is so far unknown. Great care must be taken in analysis and interpretation of obtained data, particularly if the obtained distribution is not normal. It has been suggested that 200 adult samples should be used to determine reference range. The numbers of samples that would be needed to establish reference values for children in narrowly defined age groups are not feasible. However, to circumvent this problem, we provided a 95\% confidence interval for both the lower and upper limits of ranges obtained. While it does not increase the precision of data in a manner that an increase in sample size would, the confidence interval does give a good indication of the accuracy of the presented values and makes the data useful for comparison purposes. Appropriate age-dependent control groups are essential in any study of these molecules in children. Ideally, each laboratory should establish their own reference ranges. The appropriate age related values must be known for the markers of interest to avoid the misinterpretation of obtained data and finally the faulty clinical decision.

\section{References}

1. Banks RE, Gearing AJH, Hemingway IK, Norfolk DR, Perren TJ, Selby PJ. Circulating intercellular adhesion molecule-1 (sICAM-1), E-selectin and vascular cell adhesion molecule-1 (VCAM-1) in human malignancies. $\mathrm{Br} \mathrm{J}$ Cancer 1993;68:122-4

2. Blann AD, McCollum ChN. Circulating endothelial cell/ leukocyte adhesion molecules in atherosclerosis. Thrombosis and Haemostasis 1994;72:151-4.

3. Blann AD, McCollum ChN, Steiner M, Jayson MIV. Circulating adhesion molecules in inflammatory and atherosclerotic vascular disease. Immunol Today 1995; 16:251-2.

4. Carlos TM, Harlan JM. Leukocyte-endothelial adhesion molecules. Blood 1994:84:2068-101.
5. Carson CW, Beall LD, Hunder GG, Johnson CHM, Newman W. Serum ELAM-1 is increased in vasculitis, scleroderma, and systemic lupus erythematosus. J Rheumatol 1993;20:809-14.

6. Czech W, Schopf E, Kapp A. Soluble E-selectin in sera of patients with atopic dermatitis and psoriasis - correlation with disease activity. $\mathrm{Br} \mathrm{J}$ Dermatol 1996; 134:17-21.

7. Gearing AJH, Hemingway I, Pigott R, Hughes J, Rees AJ, Cashman SJ. Soluble forms of vascular adhesion molecules, E-selectin, ICAM-1 and VCAM-1: Pathological significance. Ann N Y Acad Sci 1992;667:324-31.

8. Gearing AJH, Newman W. Circulating adhesion molecules in disease. Immunol Today 1993; 14:506-12.

9. Gorski A. The role of cell adhesion molecules in immunopathology. Immunol Today 1994; 15:251-5.

10. Jilma B, Eichler HG, Stohlawetz $P$ et al. Effects of exercise on circulating vascular adhesion molecules in healthy men. Immunobiology 1997;197:505-12.

11. Johanessen AC, Cuida M, Halse AK, Jonsson R. Soluble adhesion molecules in saliva and plasma of patients with primary Sjogren_s syndrome. Clin Rheumatol 1995; 14:S1-44

12. Krejsek J, Slezak R, Kopecky O, Derner V, Andrys C. Elevation of serum soluble intercellular adhesion molecule-1 (sICAM-1) and beta-2-microglobulin in Sjogren s syndrome. Clin Rheumatol 1997;16:149-53.

13. Kurukawa S, Imai K, Matsubara T et al. Increased levels of circulating intercelullar adhesion molecule-1 in Kawasaki diseases. Arthritis Rheum 1992;35:672-7.

14. Lez K, Tedder TF. Leukocyte interactions with vascular endothelium. J Immunol 1995; 155:525-8.

15. Maple C, Kirk G, McLaren M, Veale D, Belch JJF. A circadian variation exists for soluble levels of intercellular adhesion molecule-1 and E-selectin in healthy volunteers. Clin Sci 1998;94:537-40

16. Nash MC, Shah V, Dillon MJ. Soluble adhesion molecules and von Willebrand factor in children with Kawasaki disease. Clin Exp Immunol 1995;101:13-7.

17. Nash MC, Wade AM, Shah V, Dillon MJ. Normal levels of soluble E-selectin, soluble intercelullar adhesion molecule-1 (sICAM-1), and soluble vascular cell adhesion molecule-1 (sVCAM-1) decrease with age. Clin Exp Immunol 1996;103:167-70.

18. Newman W, Beall LD, Carson CW et al. Soluble E-selectin is found in supernatants of activated endothelial cells and is elevated in the serum of patients with septic shock. J Immunol 1993;150:644-54.

19. Rudloff S, Thomas C, Kunz C. Variations of soluble intercellular cell adhesion molecule 1 (sICAM-1) in serum of adult volunteers. Eur J Med Res 1995;1:171-

20. Sack U, Burkhardt U, Borte M, Schadlich H, Berg K, Emmrich F. Age-dependent levels of select immunological mediators in sera of healthy children. Clin Diagn Lab Immunol 1998;5:28-32.

21. Seth R, Raymond FD, Makgoba MW. Circulating ICAM-1 isoforms: diagnostic prospects for inflammatory and immune disorders. Lancet 1991;338:83-4.

22. Spronk PE, Bootsma H, Huitema MG, Limburg PC, Kallenberg CGM. Levels of soluble VCAM-1, soluble ICAM-1, and soluble E-Selectin during disease exacerbations in patients with systemic lupus erythematosus (SLE); a long term prospective study. Clin Exp Immunol 1994;97:439-44

23. Sudhoff T, Wehmeier A, Kliche KO et al. Levels of circulating endothelial adhesion molecules (sE-selectin and sVCAM-1) in adult patients with acute leukemia. Leukemia 1996;10:682-6.

Submitted March 2000.

Accepted June 2000.

RNDr. Ctirad Andrýs,

University Teaching Hospital in Hradec Králové,

Department of Clinical Immunology and Allergology, 50005 Hradec Králové, Czech Republic. e-mail: andrys@lfhk.cuni.cz 